\title{
NERVOUSNESS IN INVENTORY CONTROL
}

\section{Karl Inderfurth, Universität Bielefeld}

Inventory control systems usually are integrated in a rolling horizon planning environment by periodically processing new information on inventories, orders, and sales and accordingly adjusting forthcoming ordering decisions. Expecially errors in forecasting future product demands cause frequent replanning activities which give rise to an awkwar 1 syndrome of the planning system called nervousness.

Now, the degree of nervousness not only depends on external stochastics in sales but also on internal processing of demand information by the applied ordering policy.

In this paper for two frequently used control rules, the $(\mathrm{s}, \mathrm{nQ})$ and the $(\mathrm{s}, \mathrm{S})$ policy, an analytical investigation is performed which gives an answer to the question how the type of ordering policies and the fixing of the respective parameters influence the nervousness of the planning system. It is assumed that external disturbances are caused by a stationary stochastic demand process. Nervousness is measured by the replannir.g probability for setups in two succeeding planniug cycles.

The results of the analysis are really interesting and partly surprising. In general, it turns out that a $(\mathrm{s}, \mathrm{nQ})$-rule is connected with less nervous reactions than a $(\mathrm{s}, \mathrm{S})$-rule. The size of the reorder point $s$ has no impact on the planning instability whereas the fixed lot size $Q$ and also the minimum lot size S-s to a large extent influence the degree of nervousness. Evidently for both ordering rules planning stability is very high for extremely small as well as for very large lot sizes while it is less favourable for lots of a middle size. Especially it can be shown that nervousness is considerably high if the lot size is chosen equal or nearly equal to the forecasted demand per period. This means that using a lot-for-lot ordering rule may be rather disadvantageous with respect to a performance criterion like nervousness in planning systems. 